\title{
TRAIL produced from multiple myeloma cells is associated with osteolytic markers
}

\author{
YAWARA KAWANO ${ }^{1}$, SHIKIKO UENO ${ }^{1}$, MASAHIRO ABE ${ }^{2}$, YOSHITAKA KIKUKAWA ${ }^{1}$, \\ HIROMICHI YUKI ${ }^{1}$, KENICHI IYAMA ${ }^{3}$, YUTAKA OKUNO ${ }^{1}$, HIROAKI MITSUYA ${ }^{1}$ and HIROYUKI HATA ${ }^{1}$ \\ ${ }^{1}$ Department of Hematology, Kumamoto University School of Medicine, Kumamoto; ${ }^{2}$ Department of Medicine and \\ Bioregulatory Sciences, The University of Tokushima Graduate School of Medical Sciences, Tokushima; \\ ${ }^{3}$ Department of Surgical Pathology, Kumamoto University Hospital, Kumamoto, Japan
}

Received July 11, 2011; Accepted August 24, 2011

DOI: $10.3892 /$ or.2011.1491

\begin{abstract}
Skeletal complications represent major clinical problems in multiple myeloma (MM). MM cells are known to induce differentiation of osteoclasts and inhibit osteoblasts. Receptor activator of nuclear factor- $\kappa \mathrm{B}$ ligand (RANKL) and osteoprotegerin (OPG) are key molecules for osteoclastogenesis. Although OPG interacts with tumor necrosis factor-related apoptosis-inducing ligand (TRAIL), the contribution of TRAIL to skeletal-related events (SRE) remains a matter of debate. In the present study, we examined the role of TRAIL in MM bone lesions. Myeloma cells were purified from $56 \mathrm{MM}$ patients by CD138-immunomagnetic beads. TRAIL, DKK-1 and MIP1 $\alpha$ RNA expression in purified MM cells was analyzed by realtime PCR. Immunohistochemistry of TRAIL was performed on paraffin-embedded plasmacytoma tissue sections. The concentration of TRAIL in the serum and bone marrow plasma from MM patients was analyzed by ELISA. TRAIL expression was significantly higher in MM cells than in plasma cells from patients with monoclonal gammopathy of undetermined significance (MGUS). TRAIL staining was detected in the cytoplasm of myeloma cells. TRAIL expression in MM cells correlated with bone marrow plasma TRAIL concentration. TRAIL expression had a positive correlation with osteolytic markers, such as serum calcium and urinary deoxypyridinoline. These results suggest that TRAIL, produced from myeloma cells, may play an important role in bone resorption of $\mathrm{MM}$ patients. Inhibition of this pathway may lead to development of a new therapeutic approach preventing bone resorption in MM.
\end{abstract}

\section{Introduction}

Multiple myeloma (MM) is a B-cell neoplasia characterized by clonal expansion of malignant plasma cells in the bone

Correspondence to: Dr Hiroyuki Hata, Department of Hematology, Kumamoto University Hospital, 1-1-1 Honjo, Kumamoto City, Kumamoto 860-8556, Japan

E-mail: hata@kumamoto-u.ac.jp

Key words: multiple myeloma, TRAIL, bone resorption marrow. Fractures, skeletal-related plasmacytoma, bone pain and hypercalcemia are major skeletal-related events (SRE) in MM patients, which develop through an MM-inflicted imbalance between osteoclastogenesis and osteoblastogenesis. Osteoclastogenesis is known to be induced by the receptor activator of nuclear factor- $\kappa \beta$ ligand (RANKL) (1) and is inhibited by osteoprotegerin (OPG) (2). OPG is also known to act as a soluble inhibitor of tumor necrosis factor-related apoptosis-inducing ligand (TRAIL) (3). TRAIL, also known as APO2L, is one of the tumor necrosis factor superfamily members and is a potent stimulator of apoptosis (4). Since OPG is an inhibitor of RANKL, a possible role of TRAIL as an osteoclast inducer has been suggested $(5,6)$. Some reports have indicated a direct induction of osteoclast formation by TRAIL (7). Moreover, a contribution of TRAIL to bone lesion formation by inducing apoptosis of osteoblasts has also been reported $(8,9)$. However, the association of TRAIL with bone lesions in MM remains a matter of debate.

In the present study, we investigated the expression of TRAIL in purified MM cells and examined its association with SRE. The concentrations of TRAIL were also determined in the peripheral blood and bone marrow. Analyses were carried out to compare the significance of TRAIL relative to other SRE-related biomarkers, namely Dickkopf-1 (DKK-1) (10) and macrophage inflammatory protein-1 $\alpha$ (MIP1 $\alpha)(11)$.

\section{Materials and methods}

Cell culture. Human myeloma cell lines, KMS-12-BM (12), KMS-12-PE (12), U266 (13) and RPMI-8226 (14) were cultured in RPMI-1640 containing $10 \%$ fetal bovine serum at $37^{\circ} \mathrm{C}$ under $5 \% \mathrm{CO}_{2}$.

Patients. The subjects of the present study consisted of 56 patients with MM and 12 patients with monoclonal gammopathy of undetermined significance (MGUS). Clinical specimens were obtained from the MM and MGUS patients at the Department of Hematology, Kumamoto University Hospital. Written informed consent was obtained from all participants according to the Declaration of Helsinki. The clinical data of the patients (radiological findings, hemograms, blood chemistry and urinary deoxypyridinoline) were also 
Table I. Patient characteristics.

\begin{tabular}{lc}
\hline Parameters & $\mathrm{n}$ \\
\hline Gender (male/female) & $30 / 26$ \\
Age, years & $44-82$ (mean 63.5) \\
Type & 27 \\
IgG & 15 \\
IgA & 9 \\
BJP & 5 \\
Others & \\
DS stage & 5 \\
I & 11 \\
II & 40 \\
III & \\
\hline
\end{tabular}

IgG, immunoglobulin G; IgA, immunoglobulin A; BJP, Bence-Jones protein. DS stage; Durie-Salmon stage.

obtained. The characteristics of the $56 \mathrm{MM}$ patients are summarized in Table I.

Myeloma cell purification. After isolation of mononuclear cells from bone marrow samples using Ficoll-Paque Plus (GE Healthcare, Uppsala, Sweden), myeloma cells were purified using CD138-immunomagnetic beads (Miltenyi Biotech, Paris, France) as previously described (15).

cDNA synthesis, RT-PCR and real-time PCR. RNA was extracted from purified myeloma cells using the TRIzol reagent (Invitrogen, Carlsbad, CA). cDNA synthesis was performed using a SuperScript III First-Strand Synthesis system for RT-PCR (Invitrogen) according to the manufacturer's protocol.

The expression of TRAIL was determined using semiquantitative RT-PCR. PCR primers for TRAIL (16) and glyceraldehyde-3-phosphate dehydrogenase (GAPDH) (17) were previously reported. The PCR conditions used were as follows: initial incubation at $94^{\circ} \mathrm{C}$ for $3 \mathrm{~min}$, followed by 35 cycles of $94^{\circ} \mathrm{C}$ for $60 \mathrm{sec}, 64^{\circ} \mathrm{C}$ for $60 \mathrm{sec}$ and $72^{\circ} \mathrm{C}$ for $60 \mathrm{sec}$.

Quantitative Taqman PCR was performed using Assayon-Demand primers and the Taqman Universal PCR Master Mix reagent (Applied Biosystems, Foster City, CA). Real-time RT-PCR was performed using an ABI Prism 7700 Sequence Detection System (Applied Biosystems). The $\Delta \Delta \mathrm{CT}$ method was utilized to analyze the relative changes in gene expression. The expression levels of $\beta$-actin were used to normalize the relative expression levels of TRAIL, MIP1 $\alpha$ and DKK-1. An MM cell line, KMS-12-BM, was used as a positive control for TRAIL and MIP1 $\alpha$. The U266 cell line was used as a positive control for DKK-1. The expression of each positive control was defined as 100 .

ELISA analysis. Among the $56 \mathrm{MM}$ patients, whose TRAIL mRNA expressions were analyzed using real-time PCR, serum samples were available for 31 patients. The TRAIL concentrations in the serum samples from these MM patients and 7 healthy donors were analyzed using a TRAIL/APO2L
A
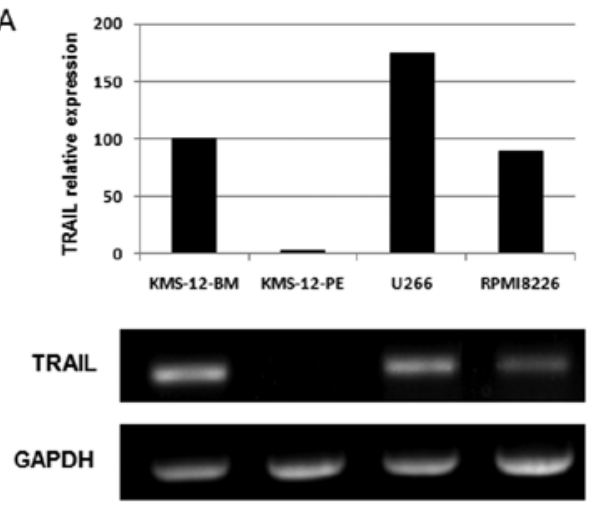

B
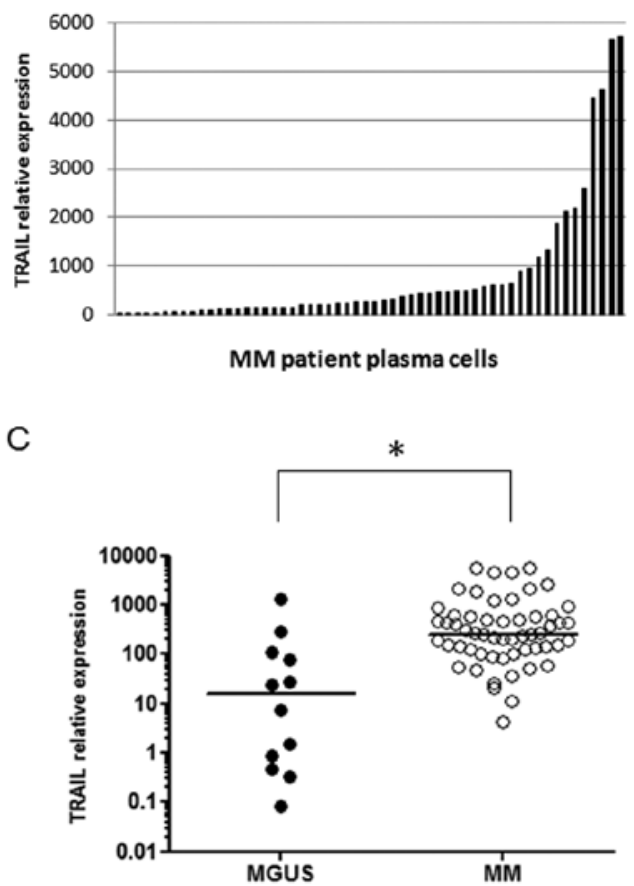

Figure 1. TRAIL mRNA expression in myeloma cells. (A) TRAIL mRNA expression in myeloma cell lines. The results of RT-PCR amplifications are shown at the bottom. The data obtained by the real-time PCR and regular PCR are correlated. (B) Expression of TRAIL in purified MM cells. The expression levels vary among the cases. (C) TRAIL expression in myeloma cells from MM and MGUS patients. The TRAIL expression levels are greater in MM patients $(\mathrm{n}=56)$ than in MGUS patients $(\mathrm{n}=12)(\mathrm{p}=0.0002$, MannWhitney U test). Horizontal bars indicate the median.

ELISA kit (Diaclone, Besançon, France) according to the manufacturer's instructions. We also analyzed the TRAIL concentrations in bone marrow plasma samples from $12 \mathrm{MM}$ patients.

Immunohistochemistry. Immunohistochemistry was performed on paraffin-embedded plasmacytoma tissue sections using a rabbit polyclonal anti-TRAIL primary antibody (clone ab2056; Abcam, Cambridge, UK) according to the manufacturer's instructions.

Statistical analysis. The expression levels of TRAIL among the 2 groups were compared by the Mann-Whitney U test. Correlations among the patient characteristics, gene expressions and TRAIL concentrations were analyzed by Spearman's 


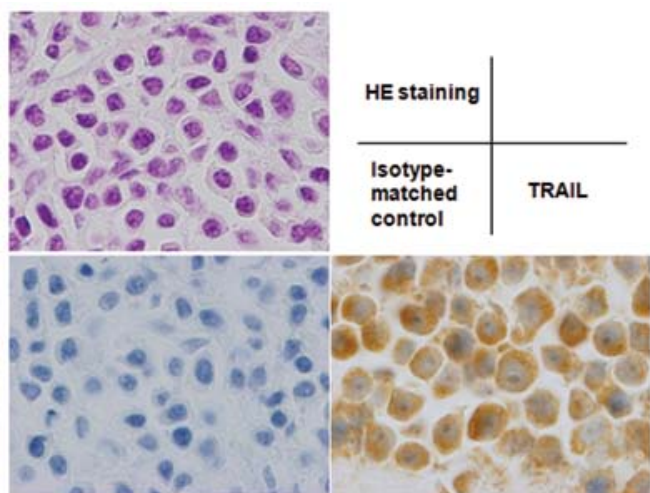

Case 1

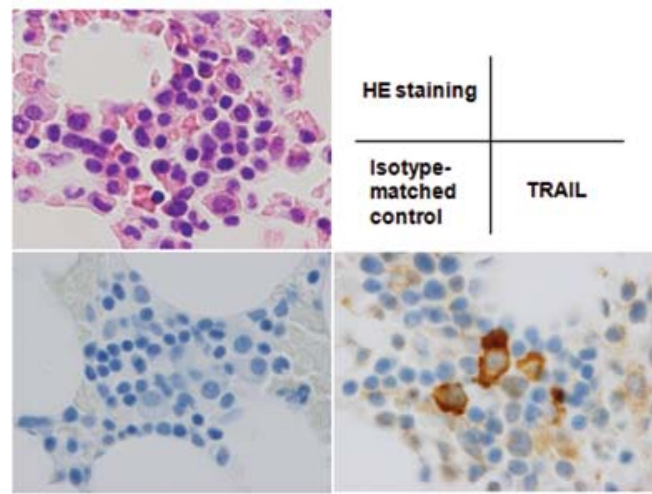

Case 2

Figure 2. TRAIL production in MM cells. Two representative cases are shown. Immunohistochemical staining reveals the existence of TRAIL in the cytoplasm. Original magnification, $\mathrm{x} 1,000$.

correlation analysis. Values of $\mathrm{p}<0.05$ were considered to indicate statistical significance.

\section{Results}

Production of TRAIL by myeloma cells. TRAIL mRNA expression was detected at various levels in myeloma cell lines (Fig. 1A) and purified primary myeloma cells (Fig. 1B). The levels of TRAIL expression were significantly higher in myeloma cells from MM patients than in plasma cells from MGUS patients ( $\mathrm{p}<0.01$; Fig. 1C). TRAIL staining was detected in the cytoplasm of myeloma cells in paraffin-embedded plasmacytoma tissues (Fig. 2). These results indicate that TRAIL is produced by myeloma cells at both the mRNA and protein levels.

TRAIL concentrations in the peripheral blood and bone marrow plasma. The serum TRAIL concentrations of 31 myeloma patients and 7 healthy donors were analyzed using ELISA. The serum TRAIL concentrations of the MM patients did not significantly differ from those of the healthy donors $(\mathrm{p}=0.51)$. No correlation was observed between the TRAIL expression in myeloma cells and the serum TRAIL concentration ( $\mathrm{rs}=0.18, \mathrm{p}=0.28$ ).

To determine the TRAIL concentrations in the bone marrow microenvironment, bone marrow plasma samples from $12 \mathrm{MM}$ patients were analyzed. The bone marrow plasma TRAIL concentration showed a significant correlation with the TRAIL expression in MM cells ( $r s=0.63$, p<0.05; Fig. 3), indicating that TRAIL may be functional in the bone marrow microenvironment.

Correlation between TRAIL and bone resorption. We further examined the associations of TRAIL with various factors involved in bone resorption, such as the serum calcium and urinary deoxypyridinoline/creatinine (U-DPD) levels. Among the $56 \mathrm{MM}$ patients, the serum calcium levels of 51 patients who were not previously treated by bisphosphonates were evaluated. There was a positive correlation between TRAIL expression and the serum calcium levels ( $r=0.28, p=0.045$; Fig. $4 A$ ). Since U-DPD is reportedly correlated with the extent of bone disease

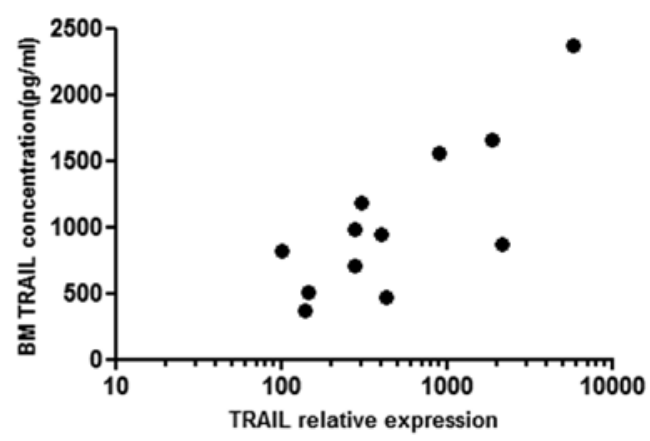

Figure 3. Correlation between TRAIL expression and TRAIL concentration in bone marrow plasma ( $\mathrm{rs}=0.63, \mathrm{p}<0.05, \mathrm{n}=12$, Spearman's correlation analysis)

in MM (18), U-DPD was measured in 22 patients. A positive correlation was also observed between TRAIL expression and the U-DPD level ( $r s=0.51, p=0.02$; Fig. 4B).

To evaluate the role of TRAIL in MM skeletal lesions, the existence of bone-associated plasmacytomas, radiation therapy or surgery for skeletal lesions were surveyed in our cohort. As shown in Fig. 4C and D, TRAIL expression was significantly higher in MM patients with bone-associated plasmacytomas $(\mathrm{p}<0.05)$ and radiation therapy or surgery for skeletal lesions $(\mathrm{p}<0.01)$.

Since DKK-1 and MIP1 $\alpha$ are well-known factors that regulate the inhibition of osteoblast differentiation and induction of osteoclast differentiation, respectively, we further compared the expressions of TRAIL, DKK-1 and MIP1 $\alpha$ in MM cells from $56 \mathrm{MM}$ patients. DKK-1 expression did not correlate with serum calcium level ( $\mathrm{rs}=0.18, \mathrm{p}=0.21)$ or U-DPD levels $(\mathrm{rs}=0.23, \mathrm{p}=0.26)$. MIP1 $\alpha$ expression correlated with serum calcium levels ( $\mathrm{rs}=0.36, \mathrm{p}=0.01)$ and U-DPD level ( $\mathrm{rs}=0.48$, $\mathrm{p}=0.028$ ) but no significant differences were observed between MIP1 $\alpha$ expression and the existence of bone-associated plasmacytomas $(\mathrm{p}=0.64)$ or with therapy for skeletal lesions $(\mathrm{p}=0.59)$. Interestingly, TRAIL significantly correlated to all of these parameters; patients with bone-associated plasmacytomas $(\mathrm{p}<0.05)$, radiation therapy or surgery for skeletal lesions $(\mathrm{p}<0.01)$, serum calcium level $(\mathrm{rs}=0.28, \mathrm{p}=0.045)$ 
A

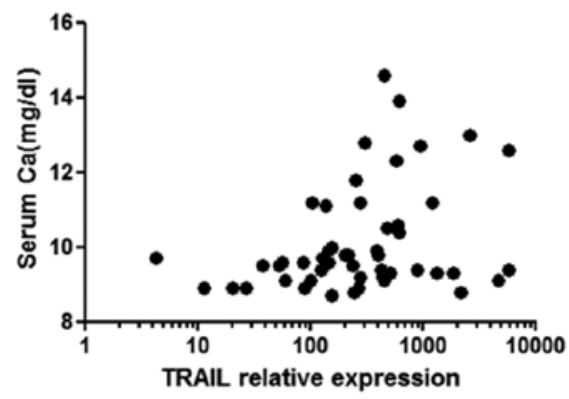

C

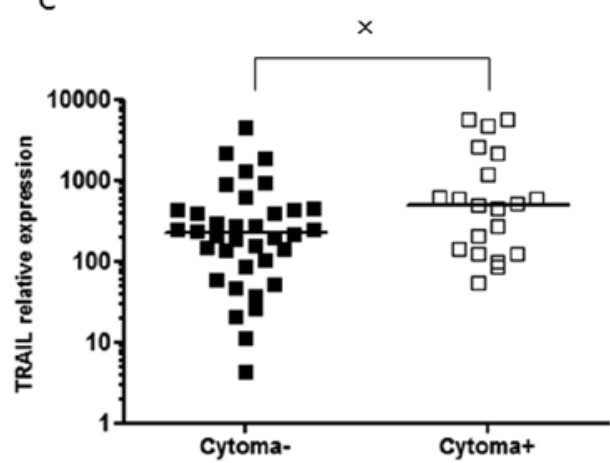

B

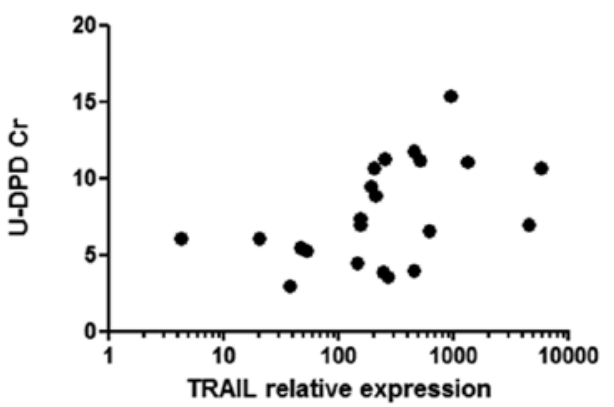

D

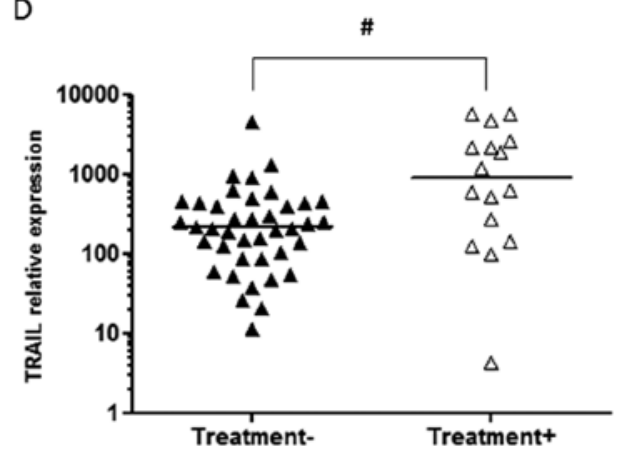

Figure 4. TRAIL expression and SRE. (A) Correlation between TRAIL expression and the serum calcium levels ( $r s=0.28$, $p<0.05$ ). (B) Correlation between TRAIL expression and the U-DPD levels $(\mathrm{rs}=0.51, \mathrm{p}<0.05)$. (C) Higher TRAIL expression level in MM patients with bone-associated plasmacytomas (Cytoma+) than in patients without bone-associated plasmacytomas (Cytoma-) $\left({ }^{\times} \mathrm{p}=0.045\right)$. (D) Higher TRAIL expression level in MM patients with radiation therapy or surgery for skeletal lesions (Treatment+) than patients without radiation therapy or surgery for skeletal lesions (Treatment-) $\left({ }^{*} \mathrm{p}=0.004\right)$. Horizontal bars indicate the median.

Table II. Summary of gene expressions and bone resorption-related parameters.

\begin{tabular}{|c|c|c|c|}
\hline Parameters & DKK-1 & MIP1 $\alpha$ & TRAIL \\
\hline Plasmacytoma & $\mathrm{p}=0.4$ & $\mathrm{p}=0.64$ & $p=0.045$ \\
\hline Intervention & $\mathrm{p}=0.33$ & $\mathrm{p}=0.59$ & $\mathrm{p}<0.01$ \\
\hline Serum calcium & $\mathrm{rs}=0.18, \mathrm{p}=0.19$ & $r s=0.36, p=0.01$ & $\mathrm{rs}=0.28, \mathrm{p}=0.045$ \\
\hline Urine DPD & $\mathrm{rs}=0.23, \mathrm{p}=0.29$ & $\mathrm{rs}=0.48, \mathrm{p}=0.028$ & $\mathrm{rs}=0.51, \mathrm{p}=0.02$ \\
\hline
\end{tabular}

MIP1 $\alpha$, macrophage inflammatory protein-1 $\alpha$; DKK-1, Dickkopf-1; TRAIL, tumor necrosis factor-related apoptosis-inducing ligand; Cytoma, bone-associated plasmacytoma; intervention, radiation therapy or surgery for skeletal lesions; Ca, serum calcium level; U-DPD, urinary deoxypyridinoline/creatinine. Results showing $\mathrm{p}<0.05$ are indicated in bold.

and U-DPD ( $\mathrm{rs}=0.51, \mathrm{p}=0.02)$. These analyses revealed that TRAIL was superior to DKK-1 or MIP1 $\alpha$ for predicting bonerelated problems. The data are summarized in Table II.

Since a previous report indicated that TRAIL is a major pathogenic mechanism for anemia in MM patients (19), we evaluated the association between TRAIL expression levels and hemoglobin levels. However, no association was observed between these two factors ( $r=0.0017, p=0.99$ ). The number of platelets showed no correlation with TRAIL expression (rs=0.0085, $\mathrm{p}=0.95$ ).

Changes in TRAIL expression during the clinical course of three patients. We carried out analyses during the clinical course of three patients to examine whether TRAIL expression changed in association with the disease status (Fig. 5). In cases 1 and 2,TRAIL expression increased $\sim 10$-fold. In case 1 , bone-associated plasmacytoma requiring irradiation appeared. Moreover, osteolytic regions increased despite chemotherapy. In case 2, back pain and U-DPD markedly increased although no fractures, osteolytic lesions or plasmacytoma were detected by regular examinations. Case 3 , who had hypercalcemia on admission which improved after chemotherapy, showed an $\sim 100$-fold decrease in TRAIL expression. These results suggest that serum calcium or urine DPD levels vary according to the TRAIL expression.

\section{Discussion}

Our analyses indicate the production of TRAIL by myeloma cells at the mRNA and protein levels. Although there are only 

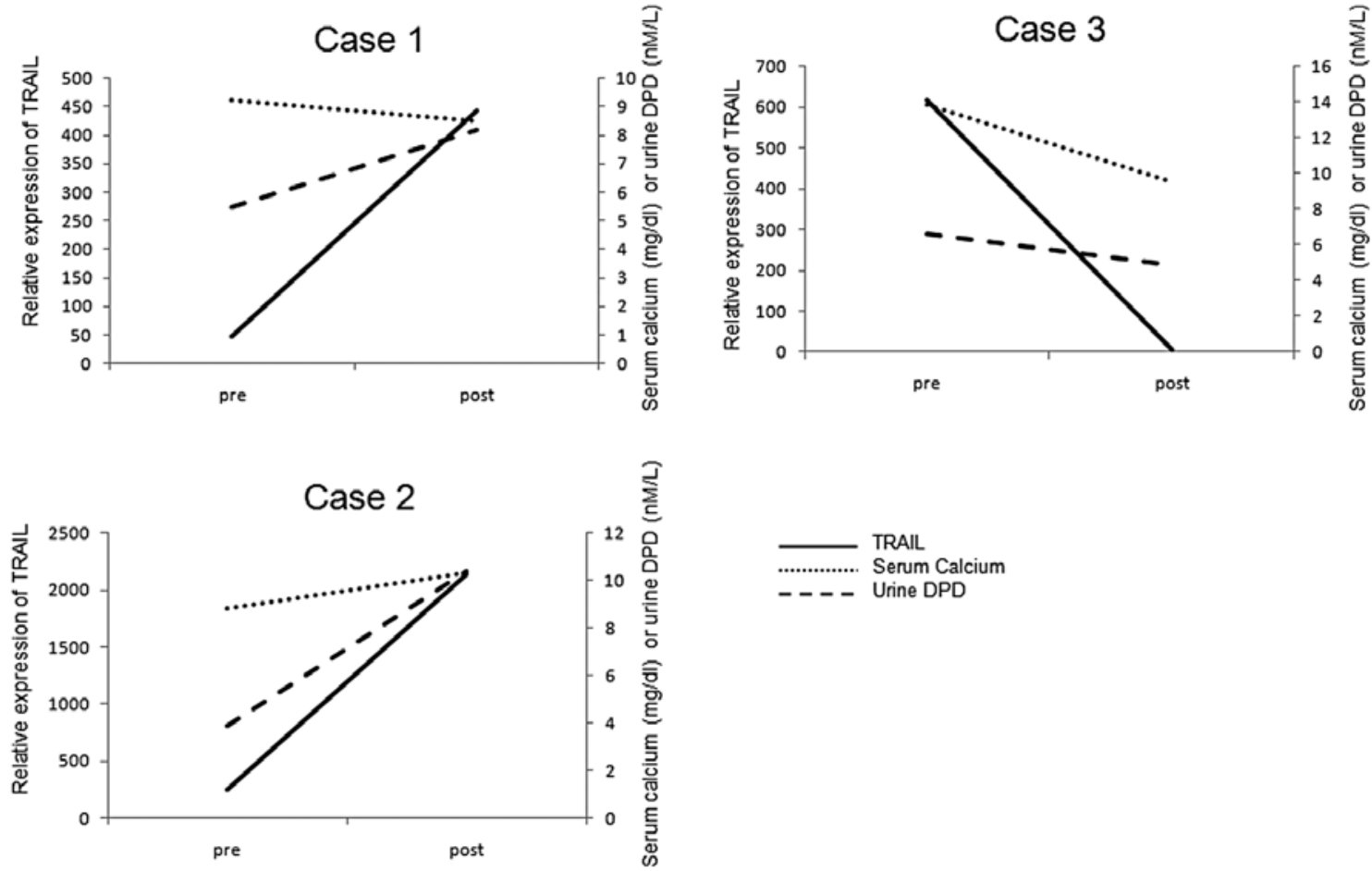

Figure 5. Changes of parameters during the clinical course. Expression of TRAIL mRNA, serum calcium concentration and urine DPD levels at pre and post treatment are shown. Cases 1 and 2 showed elevation of all these parameters while improvement of parameters was found in case 3 .

a few reports showing TRAIL production by MM cells, our finding is compatible with a previous report showing expression of TRAIL in myeloma cells based on analysis of the gene expression profile. Jourdan et al reported that TRAIL was one of the major up-regulated genes among the 58 anti- and pro-apoptotic proteins in purified myeloma cells (20). TRAIL was also one of the up-regulated genes in a hyperdiploid (HY) group, as well as DKK-1, in a University of Arkansas microarray analysis (21). The HOVON-65/GMMG-HD4 classification added three new classifications to the University of Arkansas classification (22). In this classification, TRAIL was reported to be one of the down-regulated genes in the MAF/ MAFB (MF) cluster, which showed the lowest incidence of bone lesions. These reports also support our findings.

Although the serum TRAIL concentrations were not correlated with TRAIL mRNA expression levels in myeloma cells, the bone marrow plasma TRAIL concentrations were correlated with TRAIL mRNA expression levels in myeloma cells. These data strongly suggest that TRAIL should be maintained at higher concentrations in the bone marrow microenvironment.

On the other hand, the DKK-1 expression in MM cells did not show an association with the bone resorption in our cohort. Since DKK-1 suppresses osteoblast differentiation (10), rather than manipulating osteoclastogenesis, DKK-1 failed to show correlations with serum calcium and U-DPD levels, which directly reflect osteoclast activation rather than osteoblast activation. On the other hand, correlations of MIP1 $\alpha$, a known direct osteoclast stimulatory factor in MM (11), with the serum calcium and U-DPD levels were observed. These results indicate that DKK-1 itself may not solely serve as a predictor of bone resorption.
TRAIL was the only factor examined that had a positive correlation with hypercalcemia, U-DPD, bone-associated plasmacytomas and therapy against skeletal lesions. These findings strongly suggest that TRAIL is a potent inducer of bone resorption. There have been some reports supporting this hypothesis (7). Vitovski et al showed that TRAIL inhibits OPG-mediated inhibition of osteoclastogenesis in vitro (5). Coluccci et al suggested that MM T cells support osteoclast formation through OPG/TRAIL interactions (6). It was also reported that TRAIL can induce osteoclast differentiation from precursor cells, indicating a direct association of TRAIL (7). A recent report suggests that TRAIL down-regulates the release of OPG by stroma cells (23). Our preliminary study showed that TRAIL at $1-100 \mathrm{ng} / \mathrm{ml}$ did not affect the viability of osteoclasts generated from human PBMCs as well as RANKL-stimulated RAW264.7 pre-osteoclastic cells (data not shown) in contrast to the induction of apoptosis in osteoblasts by TRAIL as previously reported $(8,9)$. However, the mechanisms involved in the regulation of osteoclastogenesis by TRAIL are unknown. The issue of whether TRAIL stimulates osteoclasts directly or indirectly as a consequence of inhibiting OPG or both is still a matter of debate.

TRAIL has been recognized as an apoptosis-inducing cytokine (24). The mechanism of MM cell survival from the TRAIL produced by themselves is still unknown. There is a report that c-FLIP is produced in MM cells when MM cells adhere to stromal cells and is responsible for protecting MM cells against TRAIL (25). These findings may explain how MM cells survive in the bone marrow microenvironment containing high concentrations of TRAIL.

Taken together, TRAIL may be a key molecule for inducing SRE in MM patients. Our findings may lead to the development 
of new strategies targeting TRAIL to reduce bone resorption in $\mathrm{MM}$ patients.

\section{Acknowledgements}

This work was supported by National Cancer Research and Development Fund in Japan.

\section{References}

1. Lacey DL, Timms E, Tan HL, et al: Osteoprotegerin ligand is a cytokine that regulates osteoclast differentiation and activation. Cell 93: 165-176, 1998.

2. Simonet WS, Lacey DL, Dunstan CR, et al: Osteoprotegerin: a novel secreted protein involved in the regulation of bone density. Cell 89: 309-319, 1997.

3. Emery JG, McDonnell P, Burke MB, et al: Osteoprotegerin is a receptor for the cytotoxic ligand TRAIL. J Biol Chem 273 14363-14367, 1998.

4. Pitti RM, Marsters SA, Ruppert S, Donahue CJ, Moore A and Ashkenazi A: Induction of apoptosis by Apo-2 ligand, a new member of the tumor necrosis factor cytokine family. J Biol Chem 271: 12687-12690, 1996.

5. Vitovski S, Phillips JS, Sayers J and Croucher PI: Investigating the interaction between osteoprotegerin and receptor activator of NF-kappaB or tumor necrosis factor-related apoptosis-inducing ligand: evidence for a pivotal role for osteoprotegerin in regulating two distinct pathways. J Biol Chem 282: 31601-31609, 2007.

6. Colucci S, Brunetti G, Rizzi R, et al: T cells support osteoclastogenesis in an in vitro model derived from human multiple myeloma bone disease: the role of the OPG/TRAIL interaction. Blood 104: 3722-3730, 2004

7. Yen ML, Tsai HF, Wu YY, Hwa HL, Lee BH and Hsu PN: TNF-related apoptosis-inducing ligand (TRAIL) induces osteoclast differentiation from monocyte/macrophage lineage precursor cells. Mol Immunol 45: 2205-2213, 2008.

8. Silvestris F, Cafforio P, Tucci M, Grinello D and Dammacco F: Upregulation of osteoblast apoptosis by malignant plasma cells: a role in myeloma bone disease. Br J Haematol 122: 39-52, 2003.

9. Tinhofer I,Biedermann R, Krismer M, Crazzolara R and Greil R: A role of TRAIL in killing osteoblasts by myeloma cells. FASEB J 20: 759-761, 2006.

10. Tian E, Zhan F, Walker R, et al: The role of the Wnt-signaling antagonist DKK1 in the development of osteolytic lesions in multiple myeloma. N Engl J Med 349: 2483-2494, 2003.

11. Abe M, Hiura K, Wilde J, et al: Role for macrophage inflammatory protein (MIP)-1alpha and MIP-1beta in the development of osteolytic lesions in multiple myeloma. Blood 100: 2195-2202, 2002.
12. Ohtsuki T, Yawata Y, Wada H, Sugihara T, Mori M and Namba M: Two human myeloma cell lines, amylase-producing KMS-12-PE and amylase-non-producing KMS-12-BM, were established from a patient, having the same chromosome marker, $\mathrm{t}(11 ; 14)(\mathrm{q} 13 ; \mathrm{q} 32)$. Br J Haematol 73: 199-204, 1989.

13. Ikeyama S, Nakagawa S, Arakawa M, Sugino $H$ and Kakinuma A: Purification and characterization of IgE produced by human myeloma cell line, U266. Mol Immunol 23: 159-167, 1986.

14. Matsuoka Y, Moore GE, Yagi Y and Pressman D: Production of free light chains of immunoglobulin by a hematopoietic cell line derived from a patient with multiple myeloma. Proc Soc Exp Biol Med 125: 1246-1250, 1967.

15. Uneda S, Hata $\mathrm{H}$, Matsuno F, et al: Macrophage inflammatory protein-1 alpha is produced by human multiple myeloma (MM) cells and its expression correlates with bone lesions in patients with MM. Br J Haematol 120: 53-55, 2003.

16. Herrnring C, Reimer T, Jeschke U, et al: Expression of the apoptosis-inducing ligands FasL and TRAIL in malignant and benign human breast tumors. Histochem Cell Biol 113: 189-194, 2000.

17. Tatetsu H, Ueno S, Hata H, et al: Down-regulation of PU.1 by methylation of distal regulatory elements and the promoter is required for myeloma cell growth. Cancer Res 67: 5328-5336, 2007.

18. Carlson K, Larsson A, Simonsson B, Turesson I, Westin J and Ljunghall S: Evaluation of bone disease in multiple myeloma: a comparison between the resorption markers urinary deoxypyridinoline/creatinine (DPD) and serum ICTP, and an evaluation of the DPD/osteocalcin and ICTP/osteocalcin ratios. Eur J Haematol 62: 300-306, 1999.

19. Silvestris F, Cafforio P, Tucci M and Dammacco F: Negative regulation of erythroblast maturation by Fas-L(+)/TRAIL(+) highly malignant plasma cells: a major pathogenetic mechanism of anemia in multiple myeloma. Blood 99: 1305-1313, 2002.

20. Jourdan M, Reme T, Goldschmidt H, et al: Gene expression of anti- and pro-apoptotic proteins in malignant and normal plasma cells. Br J Haematol 145: 45-58, 2009.

21. Zhan F, Huang Y, Colla S, et al: The molecular classification of multiple myeloma. Blood 108: 2020-2028, 2006.

22. Broyl A, Hose D, Lokhorst H, et al: Gene expression profiling for molecular classification of multiple myeloma in newly diagnosed patients. Blood 116: 2543-2553, 2010.

23. Corallini F, Celeghini C, Rimondi E, et al: TRAIL down-regulates the release of osteoprotegerin (OPG) by primary stromal cells. J Cell Physiol 226: 2279-2286, 2011.

24. Wiley SR, Schooley K, Smolak PJ, et al: Identification and characterization of a new member of the TNF family that induces apoptosis. Immunity 3: 673-682, 1995.

25. Perez LE, Parquet N, Shain K, et al: Bone marrow stroma confers resistance to Apo2 ligand/TRAIL in multiple myeloma in part by regulating c-FLIP. J Immunol 180: 1545-1555, 2008. 